\title{
Anti-Inflammatory Mechanism of Astragaloside IV in the Recurrence of Asthma: Critical Role of Memory T Cells and OX40/OX40L Signaling Pathway
}

\section{Qingqing Yang}

Shanghai Public Health Clinical Center Affiliated to Fudan University

\section{Hongying Zhang}

Institute of Integrated Traditional Chinese and Weatern Medicine, Huashan Hospital Affiliated to Fudan University

\section{Jing Sun}

Institute of Integrated Traditional Chinese and Western Medicine, Huashan Hospital Affiliated to Fudan University

\section{Jingcheng Dong}

Integrated of Integrated Traditional Chinese and Western Meicine, Huashan Hospital Affiliated to Fudan University

Lingwen Kong ( $\square$ lingwenkong@163.com )

Huashan Hospital Fudan University https://orcid.org/0000-0002-4663-555X

\section{Research Article}

Keywords: asthma recurrence, CC chemokine receptor (CCR) 7, memory T cells, Astragaloside IV

Posted Date: December 10th, 2021

DOl: https://doi.org/10.21203/rs.3.rs-794285/v1

License: (1) (i) This work is licensed under a Creative Commons Attribution 4.0 International License. Read Full License 


\section{Abstract}

The recurrence of asthma is partly mediated by central memory CD4 $(+) \mathrm{T}$ cells $\left(\mathrm{T}_{\mathrm{CM}}\right)$ that promote lung inflammation through the production of effector $T$ cells. Targeting the expansion of pathogenic $\mathrm{T}_{\mathrm{CM}}$ (central memory CD4(+) T cells) is a promising therapeutic strategy to block production of effector $\mathrm{T}$ cells. The study aimed to evaluate the regulatory effects of Astragaloside IV (AS-IV) on $\mathrm{T}_{\mathrm{CM}} \mathrm{S}$ and try to explore the anti-inflammatory mechanism of AS-IV in asthmatic mice. We developed a murine model of asthma by ovalbumin(OVA) challenge. Flow cytometry was used to determine the counts of CD4(+) memory T cells subgroups. Pulmonary tests, inflammatory cytokines in blood and inflammatory cells in bronchoalveolar lavage fluid,were measured to evaluate the inflammatory response level before and after AS-IV treatment. To further determine the role of $\mathrm{T}_{\mathrm{CM}}$ in the recurrence of inflammation, $\mathrm{T}_{\mathrm{CM}}$ were isolated by Magnetic-activated cell sorting (MACS) from spleens of asthma, control, AS-IV and dexamethasone treatment mice. The isolated cells were adoptive transferred into nude mice via tail intravenous injection, respectively, and the inflammatory response level of the lung was measured after OVA challenge. The effects of AS-IV on $T_{C M}$ viability, the number of the frequency (in percent) of $C D 44^{\text {high }} \mathrm{CD} 62 \mathrm{~L}^{\text {high }}$ cells, and the expression of OX40 and OX40L were measured before and after AS-IV treatment. In circulation blood, we demonstrated increased percentages of $\mathrm{CCR} 7{ }^{\text {high }} \mathrm{CD} 62 \mathrm{~L}^{\text {low }} \mathrm{CD} 4+$ effector memory $\mathrm{T}$ cells $\left(\mathrm{T}_{\mathrm{EM}}\right)$ and decreased $C C R 77^{\text {high }} \mathrm{CD} 62 \mathrm{~L}^{\text {high }} \mathrm{CD} 4(+) \mathrm{T}_{\mathrm{CM}}$ in asthma mice. On the contrary, the $\mathrm{T}_{\mathrm{EM}}$ subgroup percentage were decreased and the $\mathrm{T}_{\mathrm{CM}}$ phenotypes were increased in asthmatic spleen. AS-IV treatment significantly decreased CD4(+) T effector phenotypes in blood and inhibited the lung inflammatory response. Additionally, the inflammation of nude mice that adoptive transferred $T_{C M}$ from AS-IV treatment asthmatic mice had relieved inflammation compared with asthmatic group. In vitro, we successfully used spleen T lymphoid cells stimulated with IL-7 and OVA to induce a central memory T cell model. $\mathrm{T}_{\mathrm{CM}} \mathrm{CO}-$ cultured with DC cells had a significantly increased expression of OX40/OX40L. AS-IV pretreatment partially inhibited the expression of OX40 signal pathway. This study indicates that AS-IV can ameliorate asthma inflammation by inhibiting the production of $\mathrm{T}_{\mathrm{EM}}$ form $\mathrm{T}_{\mathrm{CM}}$. The treatment mechanism maybe involved in the OX40/OX40L pathway.

\section{Introduction}

Persistent allergic inflammation in the lower airway may require the presence of abundant effector T cells[1]. A large number of effector cells are generated from $\mathrm{T}_{\mathrm{CM}} \mathrm{S}$ in secondary responses, thereby providing a major source of effector cells that ultimately facilitate Ags clearance[2]. $T_{C M}$ belong to memory CD4(+) T cells group, which include CC chemokine receptor (CCR) $7^{\text {high }} \mathrm{T}_{\mathrm{CM}}$ and CCR7 ${ }^{\text {low }} \mathrm{T}_{\mathrm{EM}}[3$, 4]. Both $T_{E M}$ and $T_{C M}$ can be found in the circulation. In contrast to $T_{E M}, T_{C M}$ cells can migrate to the secondary lymphoid organs and quickly proliferate in response to infiltrating antigen-presenting cells (APCs). $T_{C M}$ cells express CCR7 and L-selectin (CD62L), which regulate the recirculation of $T_{C M}$ entering into lymphoid organs when reencounter with specific Ags[4-6]. Following antigen capture in peripheral tissues, dendritic cells also upregulate CCR7 and downregulate CD62L[7, 8]. The recent research showed 
that patients with asthma had a profound increase of CCR7 ${ }^{\text {high }}$ memory CD4(+) T cells, and the frequency of CCR7 $7^{\text {high }}$ memory CD4(+) T cells was correlated with asthma severity[9]. CD44 is also used for phenotyping murine memory $T$ cell subsets, including effector memory $T$ cells $\left(T_{E M}, C D 62 L^{\text {low }}\right.$ $\left.\mathrm{CD} 44^{\text {high }}\right)$ and central memory $T$ cells $\left(\mathrm{T}_{\mathrm{CM}}, \mathrm{CD} 62 \mathrm{~L}^{\text {high }} \mathrm{CD} 44^{\text {low }}\right)$.

$\mathrm{T}_{\mathrm{CM}}$ activation is mediated not only by antigen stimulation through $\mathrm{T}$ cell receptors but also by costimulatory signals through costimulatory molecules. Among several costimulatory molecules, the tumor necrosis factor (TNF) receptor family member OX40 has an essential role in the survival and homeostasis of memory $T$ cells $[10,11]$. OX40/OX40L is an important signal pathway that mediates the apoptosis and proliferation of antigen restimulated human memory $T$ cells[12]. A previous study found that Th2 inflammations in the lung were inhibited if OX40/OX40L signaling pathway was blocked[13]. Different studies also reported that $\mathrm{OX} 40$ signals contribute to the generation of $\mathrm{T}_{E M}[14,15]$. Therefore, in this study, the expression of the OX40/OX40L costimulatory signal pathway was measured before and after the AS-IV treatment to explore the regulated mechanism. According to existing researches, the proliferation of $\mathrm{T}_{\mathrm{CM}}$ is tightly controlled by IL-7 after antigen restimulation[16, 17], so IL-7 was used to induce memory $\mathrm{T}$ cells in vitro experiments.

$\mathrm{T}_{\mathrm{CM}} \mathrm{S}$ display core molecular signatures and functional attribute characteristics of stem cells[18], however, current common asthma therapeutics, including corticosteroids, can not block $\mathrm{T}_{\mathrm{CM}}$ s differentiating in $\mathrm{T}_{\mathrm{EM}}[19,20]$. In this study, we explored the treatment mechanism of AS-IV in the regulation of proliferation of $\mathrm{T}_{\mathrm{CM}} \mathrm{s}$.

\section{Materials And Methods}

\subsection{Mice}

All mice were bred and maintained at the Animal Facility of the Fudan University of Medicine. 6 weeks female BALB/c and 5 weeks nude mice were originally obtained from the Shanghai SLAC Co. (Shanghai, China). Mice were acclimated for 1 week to the housing condition before the experiments began, and then 2-3 mice per cage housed in a laminar air flow room with a relative humidity of $55.5 \%$. Each room was maintained at $22^{\circ} \mathrm{C}$ with a light-dark cycle of $12 \mathrm{~h}$ light and $12 \mathrm{~h}$ dark throughout the experiment. Ethics statement Animal care and manipulation was in agreement with institutional guidelines, which are in accordance with the Guide for the Care and Use of Laboratory Animals. All animal experimental procedures used in this study were approved by the Fudan University of Animal Ethics Committee. All surgery was performed under sodium pentobarbital anesthesia, and all efforts were made to minimize suffering.

\subsection{Induction of asthmatic mice model}

6 weeks female BALB/c mice were developed by OVA sensitization and inhalation as described previously[21]. In brief, on days 0,7 , and 14, mice were sensitized with an intraperitoneal (i.p.) injection of 
$0.2 \mathrm{~mL}$ alum-precipitated antigen in phosphate-buffered saline (PBS) which contained $80 \mu \mathrm{g}$ of OVA mixed with $2 \mathrm{mg}$ aluminum hydroxide. After sensitization, the mice were exposed to aerosolized OVA for $30 \mathrm{~min} /$ day on days $20-24$. The concentration of OVA was $1.5 \%$ to induce the asthmatic condition. The AS-IV treatment group mice were given 40, 20, or $10 \mathrm{mg} / \mathrm{Kg}$, Astragaloside IV, respectively (Y0001171, C41H68014, molecule weight: 784.97, Winherb Medical Science Co., Ltd Shanghai, CAS 84687-43-4) (dexm $1 \mathrm{mg} / \mathrm{kg}$ or $0.9 \% \mathrm{Nacl}$ ) by intraperitoneal injection. The doses of AS-IV used in the study refer to the relevant literature and data[22,23]. The animal study protocols were approved by the Institutional Animal Care and Use Committee of Fudan University.

\subsection{The cell culture}

\subsubsection{Isolation of splenocytes}

The BALB/c mice were euthanized with amobarbital sodium. Their spleens were collected at necropsy. Each spleen was aseptically homogenized using a glass tissue grinder. The cell suspension was centrifuged at $300 \mathrm{xg}$ for 5 minutes at $4^{\circ} \mathrm{C}$. The pellet was treated with erythrocyte lysis buffer $(0.19 \mathrm{M}$ $\mathrm{NH} 4 \mathrm{Cl}$ ) for 5 to 10 minutes at $4^{\circ} \mathrm{C}$, centrifuged (as above), and washed twice with RPMI 1640 medium ( Invitrogen/Gibco BRL, Grand Island, NY, USA). Splenocytes were then suspended in complete RPMI 1640, that is, medium supplemented with $10 \%$ fetal calf serum (Invitrogen/Gibco BRL, Grand Island, NY, USA) and antibiotics (100 U/mL penicillin, $100 \mu \mathrm{g} / \mathrm{mL}$ streptomycin)(Dojindo Laboratories, Kamamashiki, Kumamoto, Japan). The viability using trypan blue (Invitrogen/Gibco BRL, Grand Island, NY, USA) exclusion was determined.

\subsubsection{The splenocytes cells culture}

The splenocytes cells were diluted in complete medium and dispensed into 96-well plates at $5 \times 10^{5}$ cells/well/100 $\mu \mathrm{L}$. The high, medium, and low doses of AS-IV used in vivo were $5 \mathrm{ug} / \mathrm{ml}, 10 \mathrm{ug} / \mathrm{ml}$, and $20 \mathrm{ug} / \mathrm{ml}$, respectively, while control wells received only the culture medium. Cells were cultured in 96-well plates (Corning Inc., New York, NY, USA.), and viability was assessed using a commercial kit (Cell Counting Kit-8, Dojindo Laboratories, Japan) in accordance with the manufacturer's instructions. The details of the protocol have been described in our previous research. All samples were analyzed in triplicate.

\subsection{Histological Scoring}

Lungs were perfused with PBS to remove blood. In experiments with airway challenge, the left lung lobe was tied off for flow cytometry and the right lobe was fixed in $10 \%$ methanal and embedded in paraffin. Sections were stained with hematoxylin and eosin (H\&E) as previously described[24].

\subsection{Magnetic-activated cell sorting}

Magnetic-activated cell sorting (MACS) were used to isolate splenocytes. Splenocytes were collected, cells were isolated using magnetic microbeads and magnetic-activated cell sorting columns according to the manufacturer's protocol(all reagents were from Miltenyi Biotec, Bergisch Gladbach, Germany). T cells 
were counted directly after MACS. T cell viability was determined by trypan blue exclusion. CD4(+) T cells and $\mathrm{T}_{\mathrm{CM}}$ purity levels were always found to be $98 \%$ and $96 \%$, respectively.

\subsection{Adoptive transfer of TCMs into nude mice}

Six groups of nude mice(5 weeks) were transfused with CD62 ${ }^{\text {high }}$ CD4(+)T cells isolated from spleen cells of OVA-stimulated asthma group, normal group, dexameathone and AS-IV(3 different doses) treated $\mathrm{BALB} / \mathrm{c}$ mice via tail intravenous injection respectively. According to the research[25], $1.0 \times 10^{6} \mathrm{~T}_{\mathrm{CM}^{\mathrm{s}}} \mathrm{in}$ $150 \mu$ l PBS were injected into nude mice i.v. through the tail vein. One day after the cell transfer, all mice were given daily challenge with OVA for 3 days, as indicated in the figure legends. Seven days after the challenge, mice were euthanized, and their spleens and lungs were collected at necropsy. Splenocytes were detected by flow cytometry and the lung tissues were stained with hematoxylin and eosin (H\&E).

\subsection{Determination of spleen weight and spleen index}

After adoptive transfer of $\mathrm{T}_{\mathrm{CM}^{S}}$ and continuous OVA stimulation for 3 days, the nude mice were terminated at the 7th day. The spleen was immediately separated. The surrounding connective tissue and fat were excluded. The organs were dried of surface moisture using filter paper and weighed. Viscera indexes for the spleen were calculated by the following formula: organ index = organ weight (mg)/body weight (g).

\subsection{Flow cytometry}

To assess circulating CD4(+) T lymphocytes and their subsets as predictors of AS-IV treatment response at baseline, $23,30,40,50,63$, or 70 days after OVA sensitization. Multicolor flow cytometry were used to

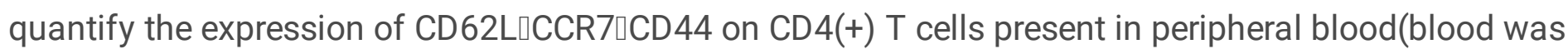
collected from the posterior eyeball vein using a glasscapillary tube). At 70 days, the mice were killed, spleen samples were collected. The cells were lysed with Pharm Lyse buffer (BD Biosciences, San Jose, CA, USA) according to the manufacturer's instructions. Cell suspensions were washed and incubated in PBS supplemented with 1\% bovine serum albumin (BSA; Sigma-Aldrich), 1\% mouse serum (Life Technologies). Cells were then stained with antibodies in 1\% BSA/1\% mouse serum/ PBS for 45 min on ice. Antibodies used were: anti-CD4- PerCP-Cy5.5, anti-CCR7-PE, anti-CD62L-APC, anti-CD44-FITC(all from BD Biosciences, San Jose, CA, USA). Data were analyzed using FlowJo. MFI (mean fluorescence intensity) was determined by subtracting the MFI of the FMO (fluorescence minus one) control from the $\mathrm{MFI}$ of the stained sample.

\subsection{Real-time PCR}

Total RNA was extracted using TRIzol (Sigma Chemical Co. St. Louis, MO, USA) according to the manufacturer's instructions. Quantification was performed with a two-step reaction process: reverse transcription (RT) and PCR. Each RT reaction consisted of 0.5 mg RNA, $2 \mathrm{~mL}$ of PrimerScript Buffer, 0.5 $\mathrm{mL}$ of oligo dT, $0.5 \mathrm{ml}$ of random 6 mers, and $0.5 \mathrm{~mL}$ of PrimerScript RT EnzymeMix I (TaKaRa Bio, Japan), in a total volume of $10 \mathrm{~mL}$. Reactions were performed in a PCR system 9700(Applied Biosystems,USA) for $15 \mathrm{~min}$ at $37^{\circ} \mathrm{C}$, followed by heat inactivation at RT for $5 \mathrm{~s}$ at $85^{\circ} \mathrm{C}$. The $10 \mathrm{~mL}$ RT 
reaction mix was then diluted $\times 10$ in nuclease-free water and held at $-20^{\circ} \mathrm{C}$. Real-time PCR instrument with $10 \mathrm{~mL}$ PCR reaction mixture that included $1 \mathrm{~mL}$ of $\mathrm{cDNA}, 5 \mathrm{~mL}$ of $2 \times$ SYBR Green I MAS-IVer (Roche, Swiss), $0.2 \mathrm{~mL}$ of forward primer, $0.2 \mathrm{~mL}$ of reverse primer and $3.6 \mathrm{~mL}$ of nucleasefree water. Reactions were incubated in a 384-well optical plate (Roche, Swiss) at $95^{\circ} \mathrm{C}$ for $10 \mathrm{~min}$, followed by 40 cycles of $95^{\circ} \mathrm{C}$ for $10 \mathrm{~s}, 60^{\circ} \mathrm{C}$ for $30 \mathrm{~s}$. Each sample was run in triplicate for analysis. At the end of the PCR cycle, melting curve analysis was performed to validate the specific generation of the expected PCR product. The primer sequences were designed in the laboratory and synthesized by Generay Biotech(Shanghai, China), based on the mRNA sequences obtained from the NCBI database. Primers used for PCR amplification are listed in Table 1. The expression levels of mRNAs were normalized to GAPDH and were calculated using the $2-\Delta \Delta$ Ct method.

Table 1

Primers used for PCR amplification

\begin{tabular}{|lll|}
\hline Gene & Forward primer & Reverse primer \\
\hline OX40 & TTCTTGCCTGTCCGCCTACT & GCTGCTGAACCCACACATACAT \\
\hline OX40L & TGCTTCTGTGCTTCATCTATGT & TGGTAACTGCTCCTCTGAGTCT \\
\hline IFN-r & CATAGATGTGGAAGAAAAGAG & AGAGTCTGAGGTAGAAAGAGATA \\
\hline IL-4 & TAGTTGTCATCCTGCTCTTCTT & CTCACTCTCTCTGGTGTTCTTC \\
\hline IL-17A & GGCTGACCCCTAAGAAAC & ATTCCTTGCTGAAAATCAATAG \\
\hline IL-13 & CAGCCTCCCCGATACCAAAAT & CCCCAGCAAAGTCTGATGTGA \\
\hline GADPH & CTTTGGCATTGTGGAAGGGC & CAGGGATGATGTTCTGGGCA \\
\hline $\mathbf{2 0}$ Wern blot analysis & \\
\hline
\end{tabular}

Spleen tissues or splenocytes were homogenized in buffer with a protease inhibitors and incubated for $30 \mathrm{~min}$ at $4^{\circ} \mathrm{C}$. Tissue or cell debris were removed by centrifugation $(12000 \times \mathrm{g}, 15 \mathrm{~min})$, then boiled $5 \mathrm{~min}$ at $98^{\circ} \mathrm{C}$ with SDS-PAGE loading buffer, and stored at $-80^{\circ} \mathrm{C}$ until used. The protein concentration was determined by BSA method. 30mg of protein were electroblotted onto a PVDF membrane, following separation on a $10 \%$ SDS-polyacrylamide gel electrophoresis. The immunoblot was incubated $1 \mathrm{~h}$ with $5 \%$ milk at room temperature, and then incubated overnight at $4^{\circ} \mathrm{C}$ with 1:1000 dilution of anti-0X40 antibody(Santa Cruz Biotech, CA, sc-21000) and 1:1000 dilution of $\beta$-actin antibody(Santa Cruz Biotechnology, sc-130656), respectively. Blots were washed three times with Tween-20/Tris-buffered saline (TTBS) and then incubated with a 1:10000 dilution of HRP-conjugated secondary antibody for $1 \mathrm{~h}$ at room temperature. The optical density (OD) of the target proteins was shown as a proportion of b-actin OD.

\subsection{Statistical analysis}


Statistical analysis was conducted using the Statistical Package for Social Sciences (SPSS v.11, Chicago, IL, USA). The significance of the differences was determined by one-way ANOVA, comparisons of parameters between 2 groups were performed with LSD or Games-Howell test. Qualitative data between groups were compared by Pearson's $\chi 2$ test or Fisher exact test, as appropriate. The data analysis of qPCr gene expression levels of the control group were set at 1-fold, and gene expression changes of other groups were expressed as the normalized "fold" change in mRNA expression compared with the control group. The significance thresholds were 0.05 in all analysis.

\section{Results}

\subsection{The anti-inflammatory effect of AS-IV on asthmatic mice}

We first measured the anti-inflammatory effects of AS-IV in an OVA-induced asthmatic mouse model. Our results showed that AS-IV significantly inhibited the lung inflammation of asthmatic mice at day 50 , as shown in Figure 1.

\subsection{AS-IV inhibited the migration of $\mathrm{T}_{\mathrm{CM}}$ from circulation blood to spleen}

We found that the central memory $T$ cells had a different distribution between blood and spleen in the asthma group after OVA challenge 50 days. The asthmatic mice had a greater percentage of CCR ${ }^{\text {high }} \mathrm{CD} 62 \mathrm{~L}^{\text {high }}$ double positive central $\mathrm{CD} 4(+)$ memory $T$ cells in the spleen, while the cell percentage was reduced in the blood. These results suggest that the asthmatic mice had a higher number of memory T cells entered from blood into lymphoid organs (Figure 2). As summarized in Figure 3, asthmatic and normal mice had a similar percentage of CD4(+) T cells in the blood and spleen. However, in the circulation blood, increased effector memory phenotype cells percentage (CCR $\left.7{ }^{\text {high }} \mathrm{CD} 62 \mathrm{~L}^{\text {low }} \mathrm{CD} 4+\right)$ was significantly reduced after AS-IV treatment, while, $\mathrm{T}_{\mathrm{CM}}$ subpopulations (CCR7 ${ }^{\text {high }} \mathrm{CD} 62 \mathrm{~L}^{\text {high }} \mathrm{CD} 4+$ ) were increased. The results showed that AS-IV treatment group has decreased the percentage of effector $T$ cells in the blood.

\subsection{The dynamic changes of memory T cells in blood before and after AS-IV treatment}

To dynamically detect the changes of memory T cells in circulating blood before and after AS-IV treatment, we treated asthmatic mice with different doses of AS-IV. The markers of CD4(+) memory T cells, CCR7, CD62L, and CD44, in the blood were dynamically measured at different time points. The results showed that the percentage of $C C R 7{ }^{\text {high }} \mathrm{CD} 62 \mathrm{~L}^{\text {high }} \mathrm{CD} 4(+)$ central memory $T$ cells was significantly inhibited after AS-IV treatment, especially after 63 days (Figure 4). Nevertheless, this percentage significantly expanded to day 70 when we discontinued the treatment (Figure 4). These results suggested that $\mathrm{T}_{\mathrm{CM}}$ was a critical medregulator for AS-IV in asthma inflammatory recurrence. 


\subsection{Adoptive transfer of asthmatic T $\mathrm{cm}$ without AS-IV treatment had more severe OVA-induced inflammation compared with AS-IV treatment asthmatic $\mathrm{T}_{\mathrm{CM}}$}

In this study, we magnetically activated a cell sorting memory $T$ cells from the spleen of BALB/c mice treated with or without AS-IV. Cells were then transferred (adoptive transfer) to nude mice. Then stimulation of OVA for 3 days, the inflammatory response level was assessed, meanwhile, the spleen cells were collected and counts of memory CD4(+)T cells were detected. The results showed that the spleen index was significantly increased in nude mice which received CD62 $L^{\text {high }} \mathrm{CD} 4(+) \mathrm{T}$ cells from the asthmatic group. Spleen weight was significantly reduced in AS-IV treated group. The lung inflammation was exacerbated in the asthma transfer group; however, inflammation was alleviated in AS-IV treated group (Figure 5).

\subsection{The treatment mechanism of AS-IV involved in the OX40/OX40L signal pathway}

In vitro experiments revealed that OVA-activated T cells stimulated with IL-7 produced a greater expansion of central memory T cells compared with IL-2 (Figure 6B), which was consistent with previous research[26]. Consequently, IL-7 was used hereafter. We successfully used spleen T lymphoid cells stimulated with IL-7 and OVA to induce a memory T cell model in vitro. Our results showed that $\mathrm{CCR}^{\text {high }}{ }^{\text {hD } 62 L^{\text {high }}} \mathrm{CD} 4(+) \mathrm{T}$ cells percentage was significantly increased in the group stimulated with OVA+ IL-7 group on day 15; AS-IV promoted CD62L expression and inhibited the effector memory T cells $\left(C C R 7^{\text {high }} \mathrm{CD} 62 \mathrm{~L}^{\text {low }}\right.$ ) proliferation (Figure 6C). As shown in Figure 6D, OVA and IL-7 stimulation resulted in a significantly increased expression of OX40/OX40L. AS-IV pretreatment partially counteracted the effects of OVA and IL-7 on OX40 signal pathway. Therefore, AS-IV treatment significantly blocked the OX40 signaling pathway, thus contributing to the anti-inflammatory effect in asthmatic mice (Figure 6D).

\section{Discussion}

$\mathrm{T}_{\mathrm{CM}}$ can more rapidly and vigorously respond to repeated exposure to antigens, thus providing the immunological memory that mediates rapid recall responses in secondary lymphoid organs and lung tissues. CCR ${ }^{\text {high }} \mathrm{CD} 4(+)$ memory $\mathrm{T}$ cells enter into secondary lymphoid organs, proliferate, and produce a higher percentage of $\mathrm{CCR} 7{ }^{\text {high }} \mathrm{CD} 62 \mathrm{~L}^{\text {low }}$ effector memory phenotype cells, which are related to the acute inflammation in lung tissues[27]. A recent report also revealed that increased CCR ${ }^{\text {high }}$ memory $\mathrm{T}$ cells were associated with asthma severity[28]. An absolute requirement of these control mechanisms is the ability to inhibit the migration and differentiation of $\mathrm{T}_{\mathrm{CM}}$. Yet, a recent report showed that in severe asthma patients, the percentage of CCR $7^{\text {high }} T$ cells in the blood was significantly lower than in the control group; thus, the distribution between lung, blood and peripheral lymphatic organs may be 
disordered in severe asthma[29]. In this study, we found that CCR ${ }^{\text {high }}$ memory T cells were significantly reduced in the asthmatic mice blood; however, it was increased in the spleen of asthmatic mice. These results indicate that $\mathrm{CCR}{ }^{\text {high }}$ memory $\mathrm{T}$ cells are important inflammatory cells of the second inflammatory response.

Previous research and our study have described that AS-IV had an anti-inflammatory effect and could prevent the recurrence of asthma[23,30]. In this study, we confirmed that CD4(+) memory $T$ cell was a key factor manipulated by AS-IV to avoid an asthma attack. A nude mouse was used to further assess the effect of AS-IV on $\mathrm{T}_{\mathrm{CM}}$ in vivo. We found that nude mice that received CD62 $\mathrm{L}^{\text {high }} \mathrm{CD} 4(+)$ splenocytes adoptive transfer from AS-IV treated asthmatic mice suffered from minor inflammation. The antiinflammatory effect was performed by inhibiting the differentiation of the effector cells.

Next, we hypothesized that $0 \times 40 / 0 \times 40 \mathrm{~L}$ signal pathway might have an important role in the differentiation process. Indeed, previous research found that $C D 4(+) T_{E M}$ of asthmatic mice significantly expressed OX40 and OX40L, where OX40 signals were indispensable for the generation of TEM precursor cells in the later stage of inflammation[14]. In this study, we found that the percentage of $\mathrm{T}_{\mathrm{CM}}$ (CCR7high, CD62 ${ }^{\text {high }}$ ) CD4(+) cells were significantly increased after the AS-IV treatment in vitro experiment. Blocking of OX40/OX40L signal pathway by AS-IV significantly inhibited the generation of $\mathrm{T}_{\mathrm{EM}}$, which was consistent with animal experiments. Increased effector phenotype $C C R 7^{\text {high }} \mathrm{CD} 62 \mathrm{~L}^{\text {low }} \mathrm{T}$ cells in asthmatic group mice were significantly reduced after AS-IV treatment, which is of vital importance as the memory phenotype $\left(\mathrm{CCR} 7{ }^{\text {high }} \mathrm{CD} 62 \mathrm{~L}^{\text {high }}\right.$ ) differentiates into the effector phenotype (CCR ${ }^{\text {high }} \mathrm{CD} 62 \mathrm{~L}^{\text {low }}$ ) will promote inflammation. AS-IV significantly inhibited $C C R 7^{\text {high }} C D 62 L^{\text {low }}$ effector T cells in the blood, which has an important role in blocking asthma attacks.

The main limitation of the current study is that the anti-inflammatory mechanism of AS-IV in the differentiation of the effector cells remained in the superficial phase; thus, future follow-up studies are needed to provide further verification for the reported findings.

\section{Conclusion}

This study indicates that AS-IV can ameliorate asthma inflammation by inhibiting $\mathrm{T}_{\mathrm{CM}}$ migration from circulation blood to spleen,while blocking differentiation from $\mathrm{T}_{\mathrm{CM}}$ to $\mathrm{T}_{\mathrm{EM}}$. The anti-inflammatory mechanism maybe involved in the OX40/OX40L pathway.

This novel finding provides support for alternative therapies for the treatment of asthma recurrence based on targeting the regulation of subpopulations of memory CD4(+) T cells.

\section{Abbreviations}

Astragaloside IV, AS-IV, CC chemokine receptor, CCR7, Central memory CD4(+) T cells, TCM, Antigen, Ags, Effector memory T cells , $T_{\mathrm{EM}}$, Antigen-presenting cells, APCs, L-selectin, CD62L, Tumor necrosis factor, 
TNF, Interleukin-7, IL-7, Ovalbumin, OVA, Intraperitoneal, i.p, Magnetic-activated cell sorting, MACS, Hematoxylin and eosin, H\&E.

\section{Declarations}

\section{Conflict of interest}

We wish to confirm that there are no known conflicts of interest associated with this publication and there has been no significant financial support for this work that could have influenced its outcome.

\section{Funding}

This work was financially supported by the National Natural Science Foundation of China (Grant No.81503483/H2704/81774074/81703829), Shanghai science and technology commission scientific research project (Grant 18401901800) and The fourth outstanding tranditional medical academic program for doctors trained in Western medicine of China.

\section{Contributions of authors}

Conceptualization: Lingwen Kong and Jingcheng Dong, Methodology: Lingwen Kong, Qingqing Yang and Hongying Zhang, Formal analysis and investigation: Lingwen Kong, Writing-original draft preparation: Lingwen Kong, Writing-review and editing: Lingwen Kong and Jingcheng Dong, Funding acquisition: Lingwen Kong and Jing Sun, Resources: Lingwen Kong, Supervision: Lingwen Kong and Jingcheng Dong.

\section{Author Declarations}

We declare that this manuscript entitled "Anti-inflammatory mechanism of Astragaloside IV in the recurrence of asthma: Critical role of memory T cells and OX40/OX40L signaling pathway" is original, has not been published before and is not currently being considered for publication elsewhere. We would like to draw the attention of the Editor to the following publications of one or more of us that refer to aspects of the manuscript presently being submitted. Where relevant copies of such publications are attached.

\section{Consent for publication}

We confirm that the manuscript has been read and approved by all named authors and that there are no other persons who satisfied the criteria for authorship but are not listed. We further confirm that the order of authors listed in the manuscript has been approved by all of us. We understand that the Corresponding Author is the sole contact for the Editorial process. She is responsible for communicating with the other authors about progress, submissions of revisions and final approval of proofs. 


\section{References}

1. Sallusto, F., Lenig, D., Forster, R., Lipp, M., Lanzavecchia, A. Two subsets of memory T lymphocyteswith distinct homing potentials and effector functions. Nature, 401(6754): 708-12, 1999.

2. Harrington, L E., Janowski, K M., Oliver, J R., Zajac, A J., Weaver, C T. Memory CD4 T cells emerge from effector T-cell progenitors. Nature, 452(7185): 356-60, 2008.

3. Geginat, J., Campagnaro, S., Sallusto, F., Lanzavecchia, A. TCR-independent proliferation and differentiation of human CD4+ T cell subsets induced by cytokines. Adv Exp Med Biol, 512: 107-12, 2002 .

4. Sallusto, F., Geginat, J., Lanzavecchia, A. Central memory and effector memory T cell subsets: function, generation, and maintenance. Annu Rev Immunol, 22: 745-63, 2004.

5. Forster, R., Schubel, A., Breitfeld, D., Kremmer, E., Renner-Muller, I., Wolf, E., Lipp, M. CCR7 coordinates the primary immune response by establishing functional microenvironments in secondary lymphoid organs. Cell, 99(1): 23-33, 1999.

6. Tough, D.F. and J. Sprent. Turnover of naive- and memory-phenotype T cells. J Exp Med, 179(4): 1127-35, 1994.

7. Bradley, L M.,Watson, S R., Swain, S L. Entry of naive CD4 T cells into peripheral lymph nodes requires L-selectin. J Exp Med, 180(6): 2401-6, 1994.

8. Trinite, B., Chan, C N., Lee, C S., Mahajan, S., Luo, Y., Muesing, M A., Folkvord, J M., Pham, M., Connick, E., Levy, D N. Suppression of Foxo1 activity and down-modulation of CD62L (L-selectin) in HIV-1 infected resting CD4 T cells. PLoS One, 9(10): e110719, 2014.

9. Gehad, A., Teague, J E., Matos, T R., Huang, V., Yang, C., Watanabe, R., O'Malley, J T., Trimble, C L Kupper, T S., Clark, R A. A primary role for human central memory cells in tissue immunosurveillance. Blood Adv, 2(3): 292-298, 2018.

10. Gramaglia, I., Weinberg, A D., Lemon, M., Croft, M. Ox-40 ligand: a potent costimulatory molecule for sustaining primary CD4 T cell responses. J Immunol, 161(12): 6510-7, 1998.

11. Song, J., So, T., Cheng, M., Tang, X., Croft, M. Sustained survivin expression from OX40 costimulatory signals drives T cell clonal expansion. Immunity, 22(5): 621-31, 2005.

12. Yamaki, S., Ine, S., Kawabe, T., Okuyama, Y., Suzuki, N., Soroosh, P., Mousavi, S F., Nagashima, H., Sun, S L., So, T., Sasaki, T., Harigae, H., Sugamura, K., Kudo, H., Wada, M., Nio, M., Ishii, N. OX40 and IL-7 play synergistic roles in the homeostatic proliferation of effector memory CD4(+) T cells. Eur $\mathrm{J}$ Immunol, 44(10): 3015-25, 2014.

13. Burrows, K E., Dumont, C., Thompson, C L., Catley, M C., Dixon, K L., Marshall, D. OX40 blockade inhibits house dust mite driven allergic lung inflammation in mice and in vitro allergic responses in humans. Eur J Immunol, 45(4): 1116-28, 2015.

14. Soroosh, P., Ine, S., Sugamura, K., Ishii, N. Differential requirements for OX40 signals on generation of effector and central memory CD4+ T cells. J Immunol, 179(8): 5014-23, 2007. 
15. Webb, G J., Hirschfield, G M., Lane, P J. OX40, OX40L and Autoimmunity: a Comprehensive Review. Clin Rev Allergy Immunol, 50(3): 312-32, 2016.

16. Colpitts, S L., Dalton, N M., Scott, P. IL-7 receptor expression provides the potential for long-term survival of both CD62Lhigh central memory T cells and Th1 effector cells during Leishmania major infection. J Immunol, 182(9): 5702-11, 2009.

17. Kueberuwa, G., Gornall, H., Alcantar-Orozco, E M., Bouvier, D., Kapacee, Z A., Hawkins, R EGilham, D E. CCR7(+) selected gene-modified T cells maintain a central memory phenotype and display enhanced persistence in peripheral blood in vivo. J Immunother Cancer, 5: 14, 2017.

18. Gattinoni, L., Klebanoff, C A., Restifo, N P. Paths to stemness: building the ultimate antitumour T cell. Nat Rev Cancer, 12(10): 671-84, 2012.

19. Wiest, M., Upchurch, K., Yin, W., Ellis, J., Xue, Y., Lanier, B., Millard, M., Joo, H., Oh, S. Clinical implications of CD4(+) T cell subsets in adult atopic asthma patients. Allergy Asthma Clin Immunol, 14: 7, 2018.

20. Shirai, T., Inui, N., Suda, T., Chida, K. Correlation between peripheral blood T-cell profiles and airway inflammation in atopic asthma. J Allergy Clin Immunol, 118(3): 622-6, 2006.

21. Wang, J., Kong, L., Luo, Q., Li, B., Wu, J., Liu, B., Wu, X., Dong, J. Dual effects of respiratory syncytial virus infections on airway inflammation by regulation of Th17/Treg responses in ovalbuminchallenged mice. Inflammation, 37(6): 1984-2005, 2014.

22. Wang, E., Wang, L., Ding, R., Zhai, M., Ge, R., Zhou, P., Wang, T., Fang, H., Wang, J., Huang, J. Astragaloside IV acts through multi-scale mechanisms to effectively reduce diabetic nephropathy. Pharmacol Res, 157: 104831, 2020.

23. Yang, C., Mo, Y., Xu, E., Wen, H., Wei, R., Li, S., Zheng, J., Li, W., Le B., Chen, Y., Pan, H., Huang, S., Wang, S., Wang, Q. Astragaloside IV ameliorates motor deficits and dopaminergic neuron degeneration via inhibiting neuroinflammation and oxidative stress in a Parkinson's disease mouse model. Int Immunopharmacol, 75: 105651, 2019.

24. Kong, L., Liu, J., Wang, J., Luo, Q., Zhang, H., Liu, B., Xu, F., Pang, Q., Liu, Y., Dong, J. Icariin inhibits TNF-alpha/IFN-gamma induced inflammatory response via inhibition of the substance $P$ and $p 38$ MAPK signaling pathway in human keratinocytes. Int Immunopharmacol, 29(2): 401-407, 2015.

25. Vooght, V., Haenen, S., Verbeken, E., Nemery, B., Hoet, P H., Vanoirbeek, J A. Successful transfer of chemical-induced asthma by adoptive transfer of low amounts of lymphocytes in a mouse model. Toxicology, 279(1-3): 85-90, 2011.

26. Schmueck-Henneresse, M., Omer, B., Shum, T., Tashiro, H., Mamonkin, M., Lapteva, N., Sharma, S., Rollins, L., Dotti, G., Reinke, P., Volk, H D., Rooney, C M. Comprehensive Approach for Identifying the T Cell Subset Origin of CD3 and CD28 Antibody-Activated Chimeric Antigen Receptor-Modified T Cells. J Immunol, 199(1): 348-362, 2017.

27. Mackay, C.R. and U.H. von Andrian. Immunology. Memory T cells--local heroes in the struggle for immunity. Science, 291(5512): 2323-4, 2001. 
28. Moaaz, M., Youssry, S., Baess, A., Abed, A., Moaaz, M. Immune signature of CCR7 + central memory T cells associates with disease severity and Immunoglobulin $\mathrm{E}$ in bronchial asthma. Eur Ann Allergy Clin Immunol, 53(3): 115-127, 2020.

29. Gluck, J., Rymarczyk, B and Rogala, B. Chemokine receptors expression on CD3+ blood cells in bronchial asthma. Adv Med Sci, 61(1): 11-7, 2016.

30. Kong, L., Zhang, H., Cao, Y., Le J., Wu, J., Liu, B., Chen, M., Du Y., Wang, J., Wang, G., Yi, T., Zhou, X., Wang, G., Miao, Q., Li, S., Zhao, N., Dong, J. The Anti-Inflammatory Effects of Invigorating Kidney and Supplementing Qi Chinese Herbal Formulae in Asthma Patients. Evid Based Complement Alternat Med, 2017: 3754145, 2017.

\section{Figures}

A

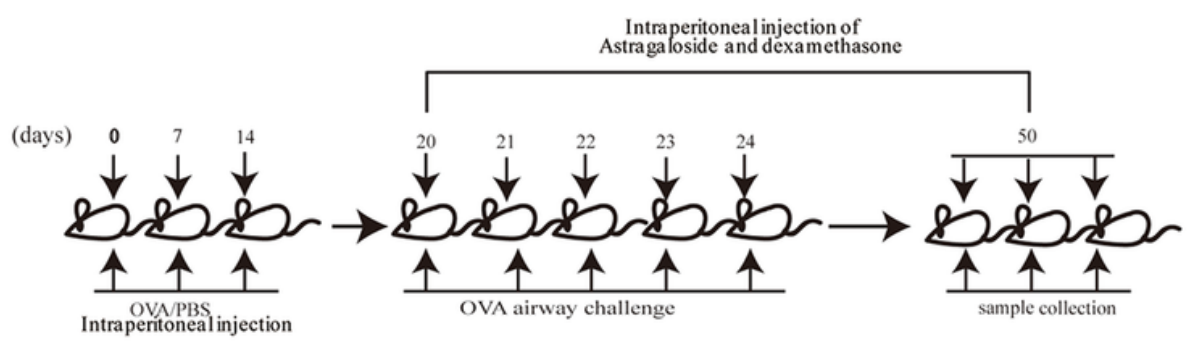

B
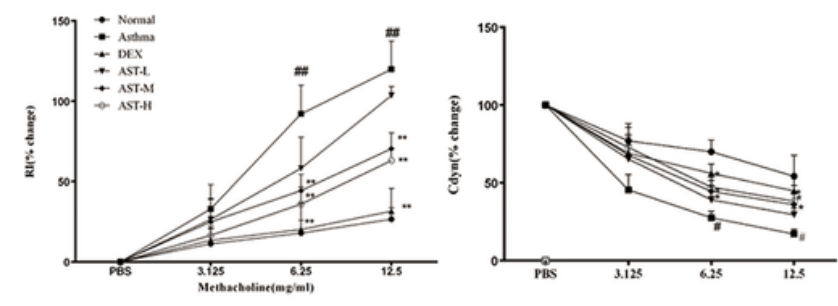

$\mathrm{C}$
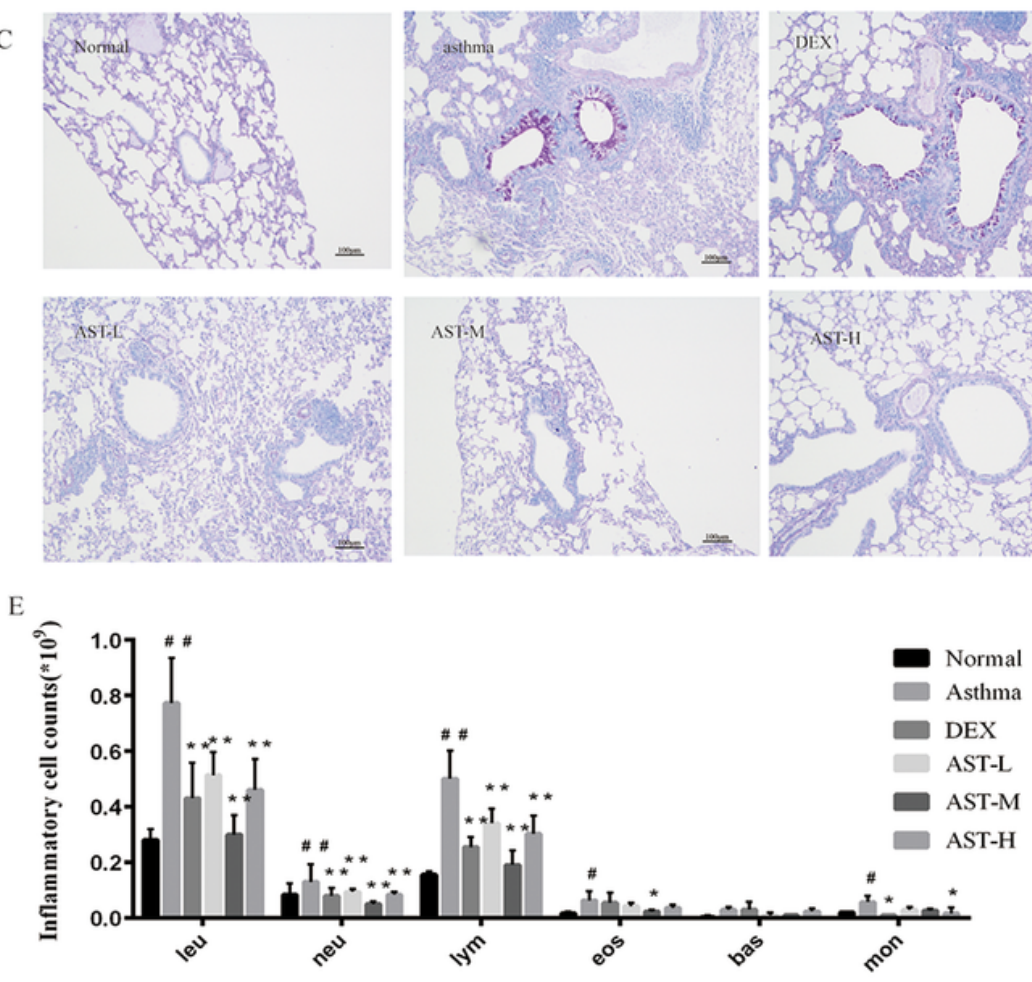

D
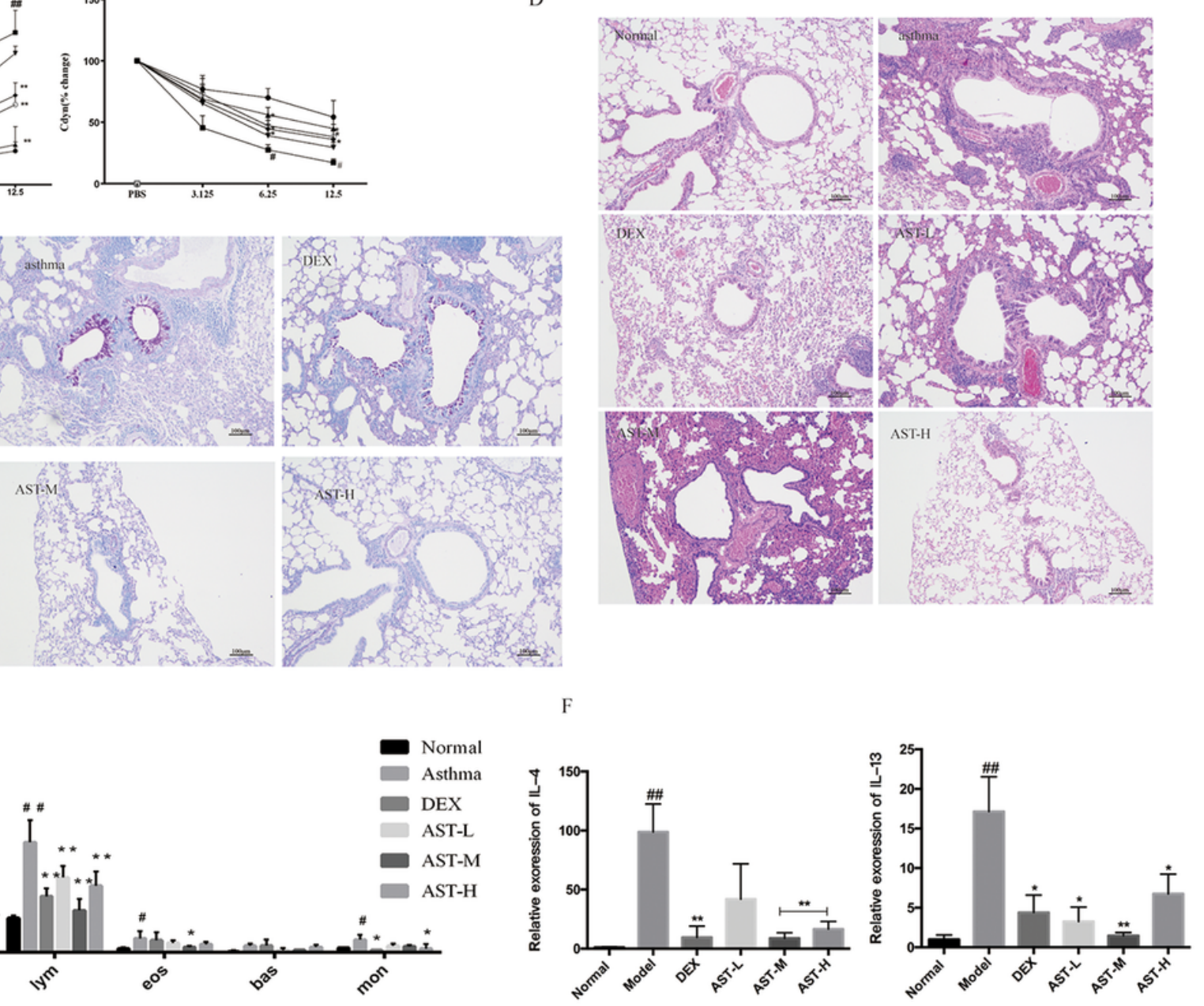
Figure 1

The anti-inflammatory effects of AS-IV on OVA-induced asthmatic mice. (A) Experimental procedure for creating our OVA-induced allergic inflammation model, (B) Airway hyperactivity response as measured to methacholine (Mch). (C) and (D)H\&E and PAS staining of the lung sections. (E)The number of various immune cell populations found in the BALF after OVA challenge. ${ }^{*} \mathrm{p}<0.05,{ }^{\star \star} \mathrm{p}<0.01$ vs asthma group, \# $p<0.05$, \#\# $p<0.01$ vs normal group.

Intraperitoneal injection of

Astraga loside and dexamethasone

A

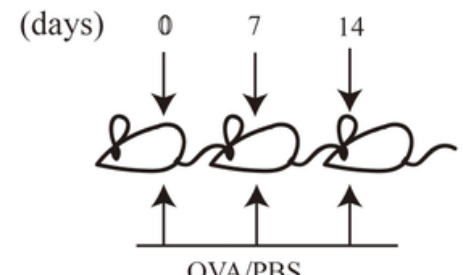

Intraperitoneal injection

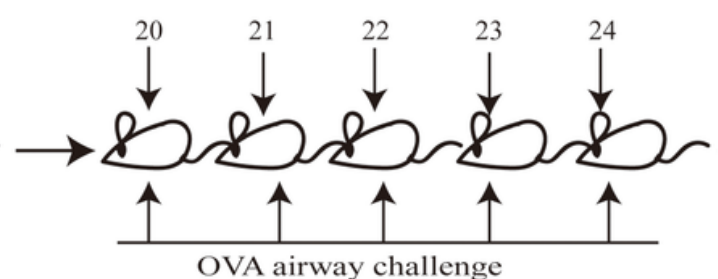

OVA airway challenge

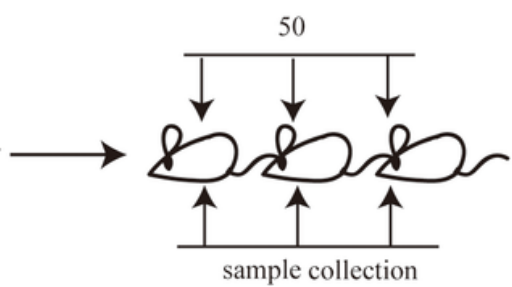

B

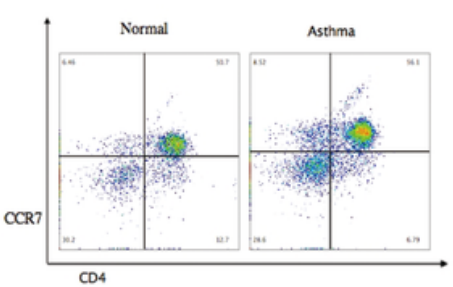

C

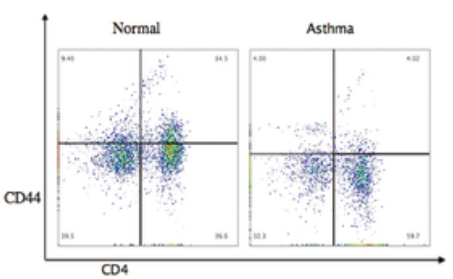

D

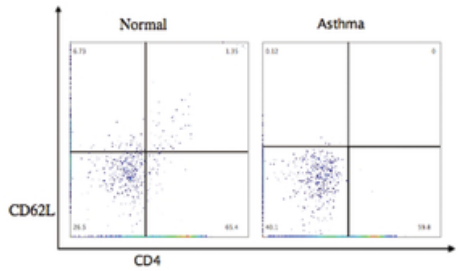

E

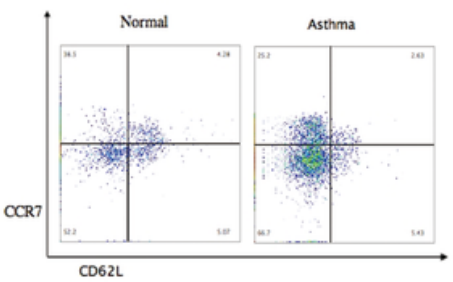

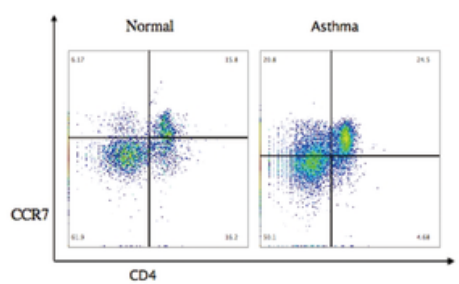
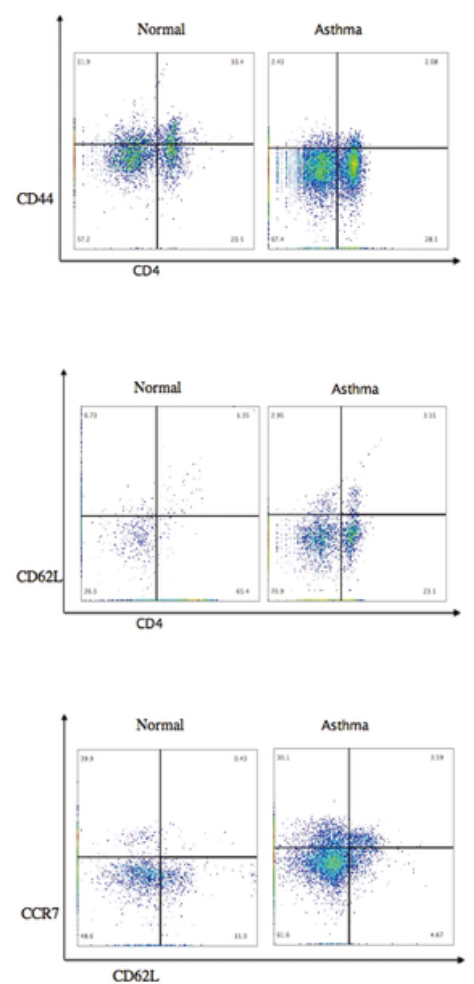

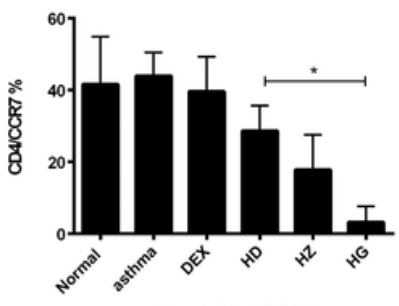

blood-CD4/CCR7

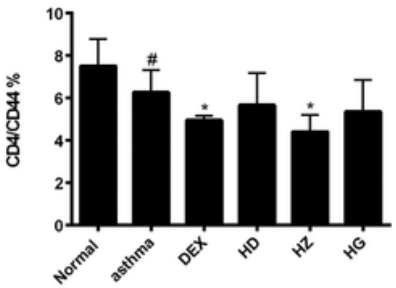

blood-CD4/CD44

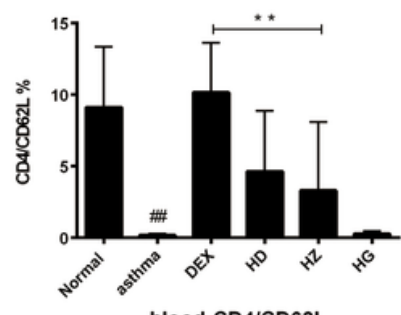

blood-CD4/CD62L

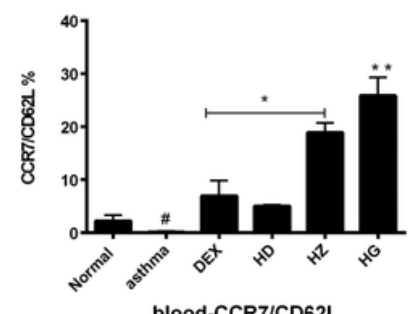

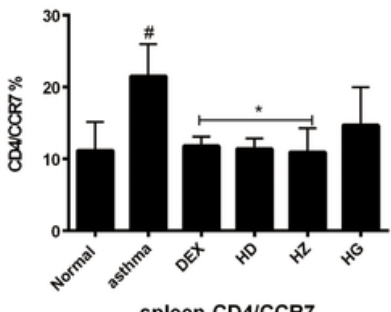

spleen-CD4/CCR7
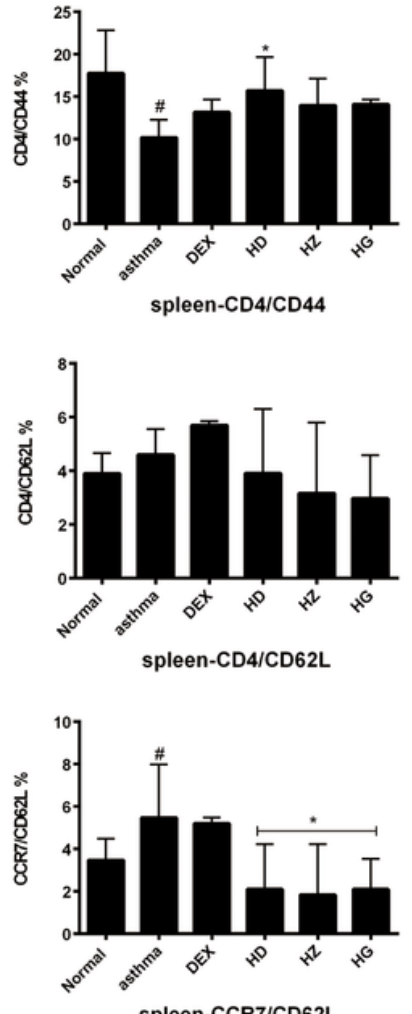

Figure 2 
A different tendency of distributions of CD4+ memory T cells in blood circulation and spleen. Blood and spleen $T$ cells were collected and measured on day 50 by flow cytometry. The percentage of CD4+ T cells in blood and spleen were similar in the asthma and normal groups(the figure was not included).(A) Experimental design to determine if central memory CD4+ T cells have different distributions between spleen and circulation (B)Numbers of the frequency (in percent) of the CCR7high CD4+ T cells in circulation blood and spleen (C) The frequency of the CD44high CD4+T cells in circulation and spleen (D). Numbers of the frequency (in percent) of the CD62Lhigh CD4+T cells in circulation and spleen (E). Numbers of the frequency (in percent) of the CCR7highCD62Lhigh CD4+T cells in circulation and spleen, ${ }^{*} \mathrm{p}<0.05$ vs normal group, ${ }^{\star *} \mathrm{p}<0.01$ vs normal group.

A

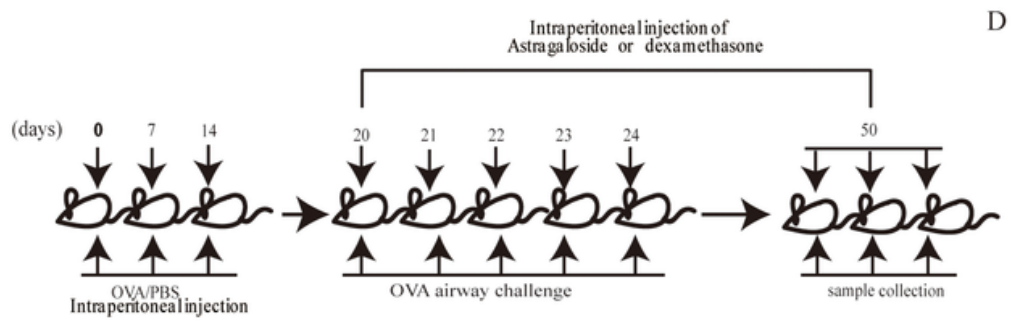

B

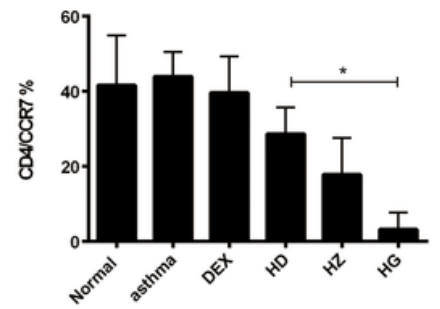

blood-CD4/CCR7

C

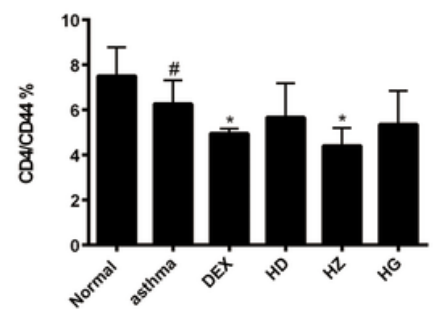

blood-CD4/CD44

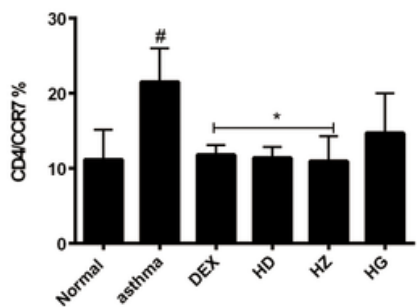

spleen-CD4/CCR7

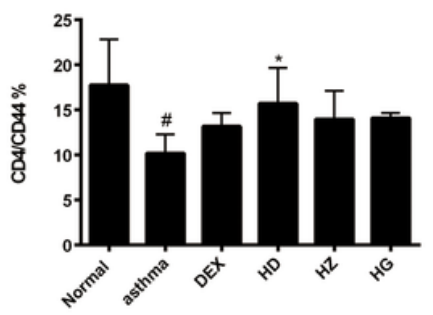

spleen-CD4/CD44

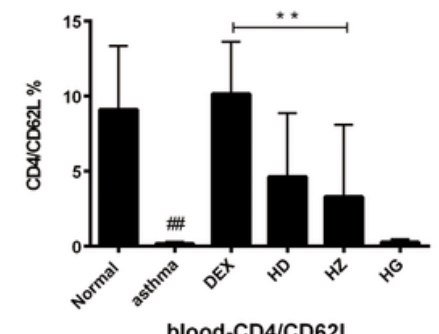

blood-CD4/CD62L

E

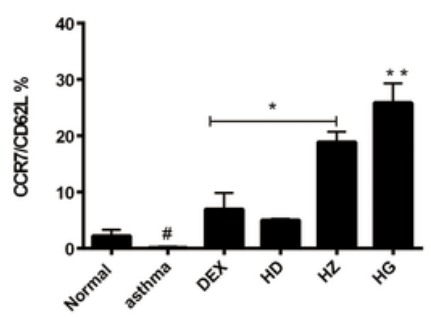

blood-CCR7/CD62L

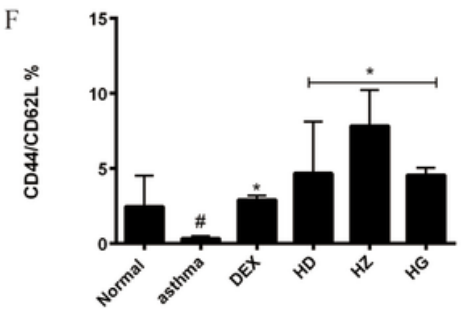

blood-CD44/CD62L
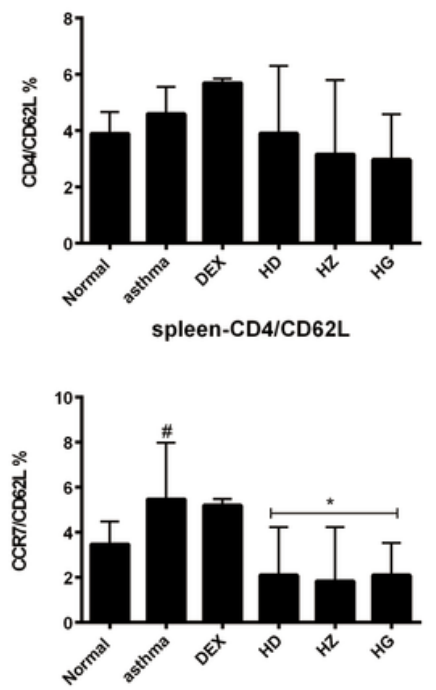

spleen-CCR7/CD62L

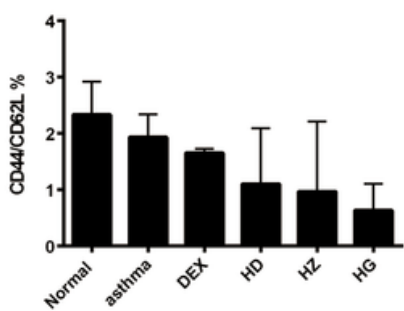

spleen-CD44/CD62L

Figure 3

Distinct profiles of the homeostatic proliferation of memory T cells after AS-IV treament. Blood and spleen $T$ cells were collected and measured on day 50 by flow cytometry. CD4+ T cells counts of blood and spleen were similar in every group, (A) Experimental design to determine whether AS-IV regulate the distributions of central memory CD4+ T cells between spleen and circulation (B) Numbers of the frequency (in percent) of the CCR7high CD4+ T cells in blood and spleen (C) The frequency of the CD44high CD4+ T cells in blood and spleen (D). Numbers of the frequency (in percent) of the CD62Lhigh $\mathrm{CD} 4+\mathrm{T}$ cells in blood and spleen, (E). Numbers of the frequency (in percent) of the CCR7highCD62Lhigh CD4+T cells in blood and spleen, $(F)$. Numbers of the frequency (in percent) of the CD44highCD62Lhigh $\mathrm{CD} 4+\mathrm{T}$ cells in blood and spleen Similar results were obtained in three independent experiments. ${ }^{*} \mathrm{p}<$ 0.05 , ${ }^{\star \star} p<0.01$ vs asthma group, $\# p<0.05$, \#\# $p<0.01$ vs normal group. 


\section{Figure 4}

AS-IV reduced expression of central memory T cells markers in circulation. (A) Experimental design to determine systemic regulate effect of AST on memory T cells in asthma mice (B) Numbers of the frequency (in percent) of the CCR7high CD4+T cells in blood circulation from different points in time after treatment, (C) Numbers of the frequency (in percent) of the CD44high CD4+T cells in blood circulation from different points in time after treatment, (D) Numbers of the frequency (in percent) of the CD62Lhigh CD4+ $T$ cells in blood circulation from different points in time after treatment, (E)Numbers of the frequency (in percent) of the CD44highCCR7high CD4+T cells in blood circulation from different points in time after treatment, $(F)$ Numbers of the frequency (in percent) of the CD44highCD62Lhigh CD4+T cells in blood circulation from different points in time after treatment, $(G)$ Numbers of the frequency (in percent) of the CCR7highCD62Lhigh CD4+T cells in blood circulation from different points in time after treatment. ${ }^{\star} p<0.05$, ${ }^{\star \star} p<0.01$ vs asthma group, \# $p<0.05$, \#\# $p<0.01$ vs normal group.

A

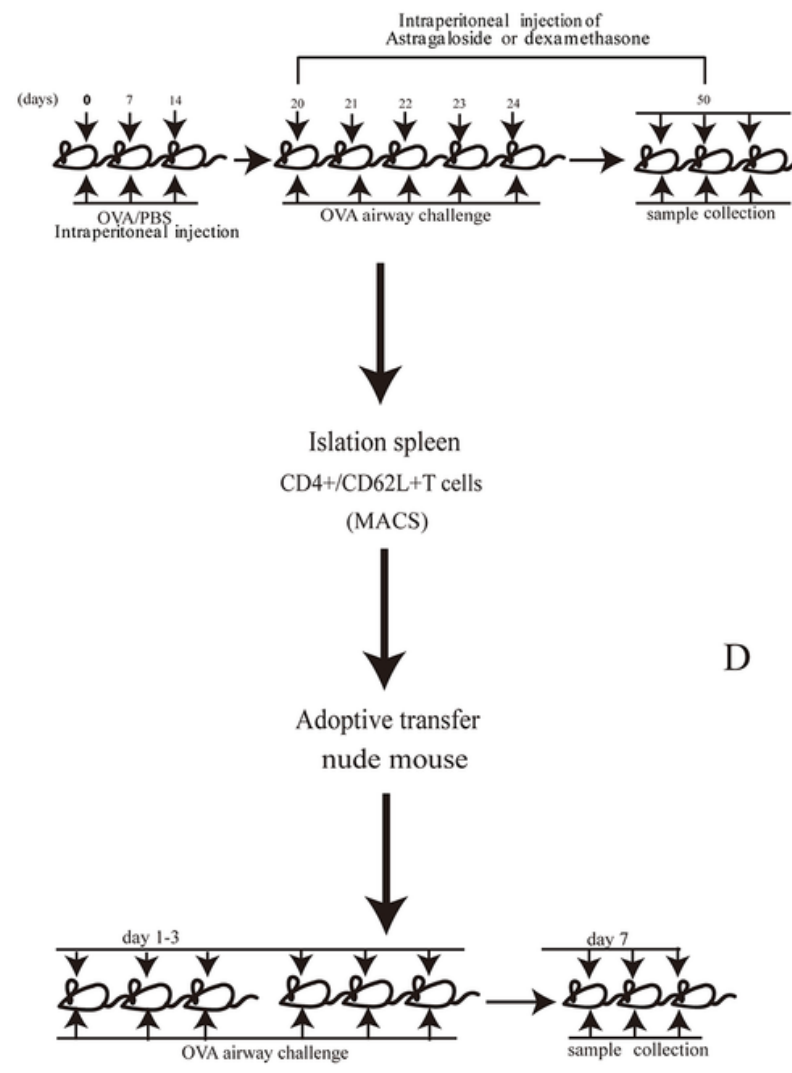

B

$\mathrm{C}$
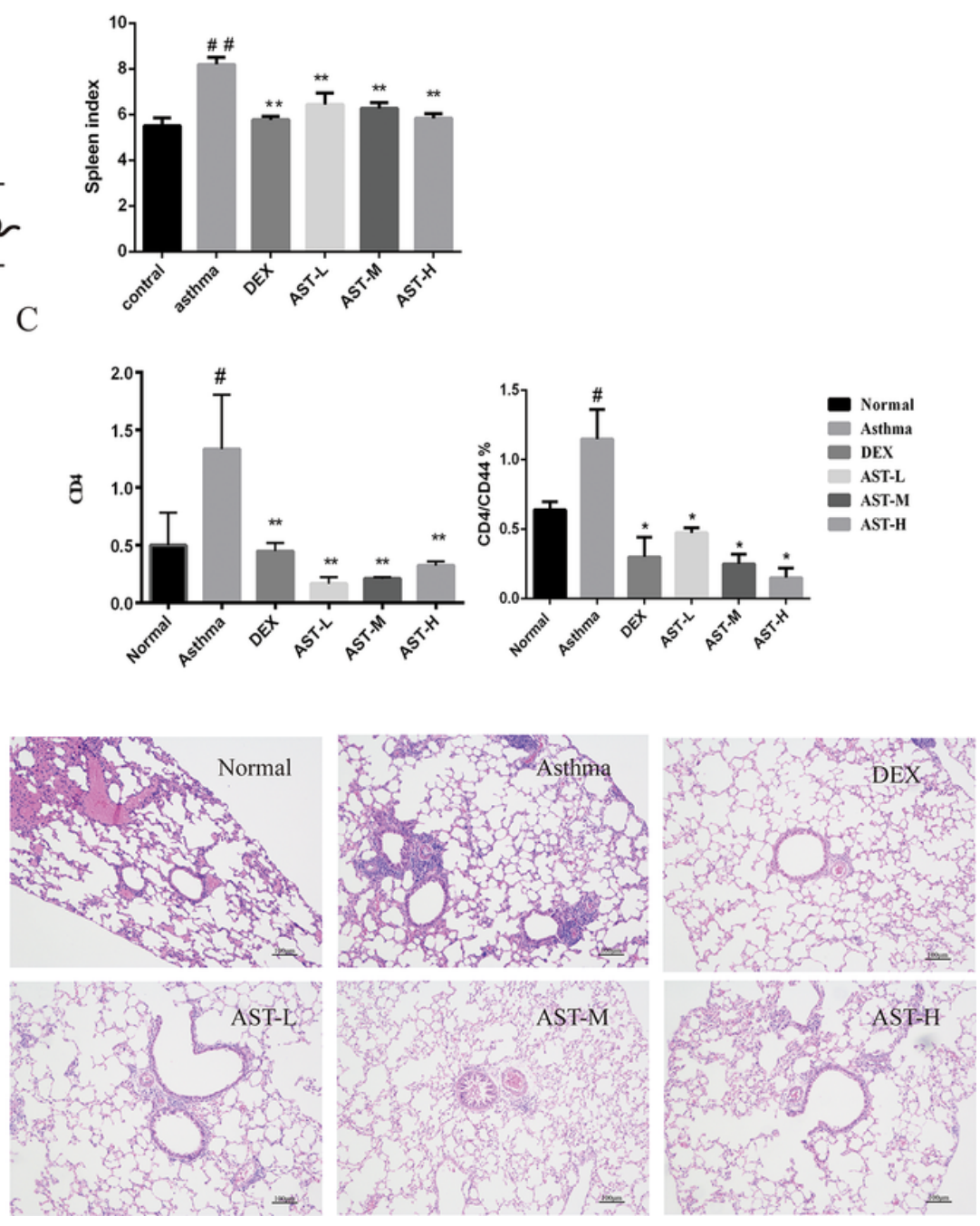

Figure 5 
The anti-inflammatory effect of AS-IV was performed by inhibiting differentiation of TCM to TEM. $1 \times 106$ CD62Lhigh CD4+ T cells were transferred into nude mice, the mice were then stimulated with OVA on day 1-3 post adoptive transfer, the inflammatory levels were measured and the distribution of memory CD4+ $T$ cells was analyzed in the indicated tissues. (A)Experimental design, (B) Spleen index after AS-IV or dexamethasone treatment, (C) Numbers of the frequency (in percent) of the CD4+T cells and CD44high CD4+ T cells in spleen, (D) H\&E staining of the lung sections. \# $p<0.05, \# \# p<0.01$ vs normal group, * $p<0.05$ vs asthma group, ** $p<0.01$ vs asthma group.

A

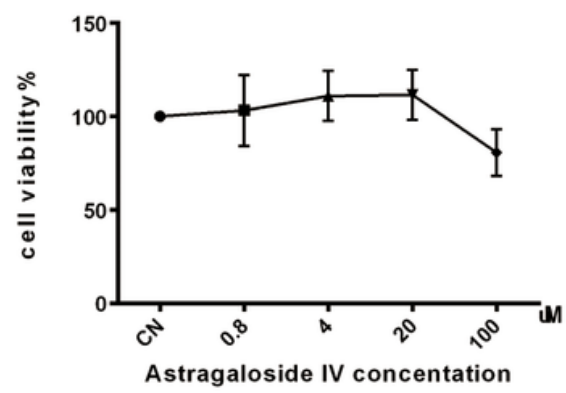

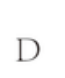
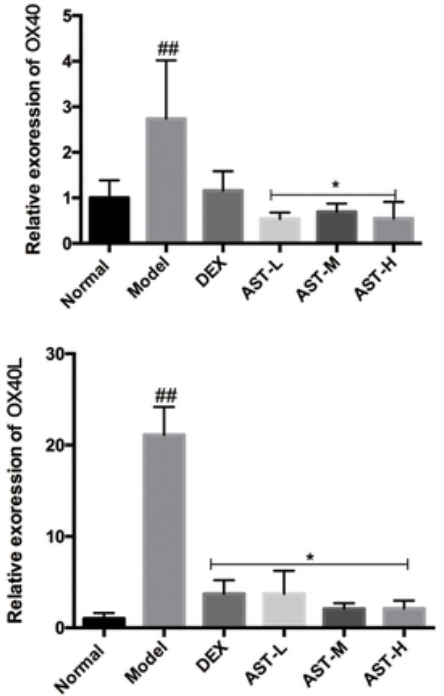

Normal Model DEX AST-L AST-M AST-H
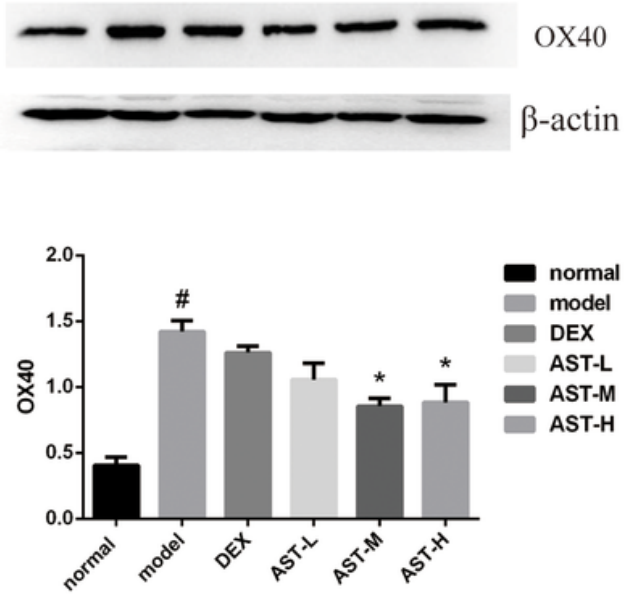

B

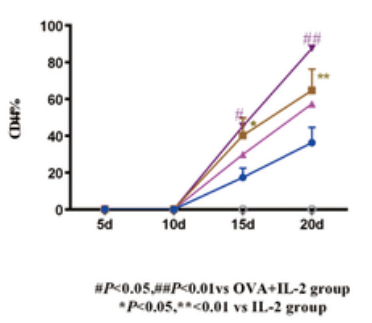

C
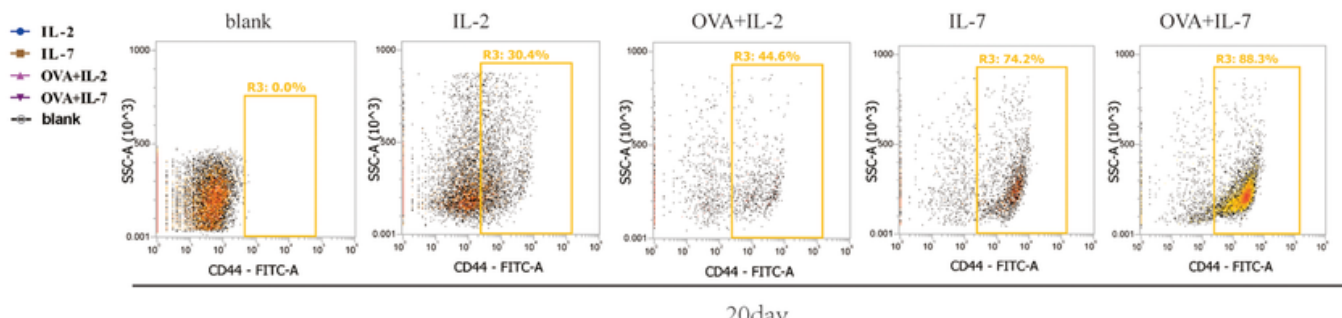

20day
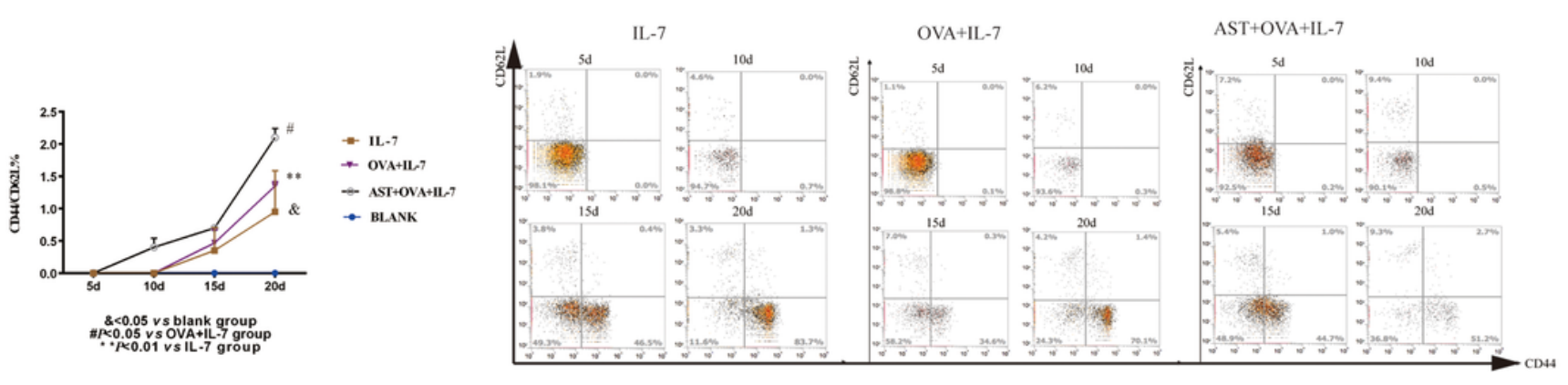

\section{Figure 6}

TCM differentiation involved in OX40/OX40L pathway regulated by AS-IV. The spleen lymphocytes were collected and co-cultured with DC cells, then stimulated with IL-7,IL-2,OVA+IL-2/IL-7 or AS-IV+OVA+IL-2/IL7.The cells were harvested at day $5,10,15,20$.(A)Effects of AS-IV on T cell viability, (B)The numbers of the frequency (in percent) of CD44high cells(TCM surface marker ), (C) The numbers of the frequency (in 
percent) of CD44highCD62Lhigh cells, (D) The mRNA and protein expression of OX40 and OX40L(day 20). \# $p<0.05, \# \# p<0.01$ vs normal group, * $p<0.05$ vs asthma group. 